\title{
Structural, Optical and Magnetic Properties of $\alpha-\mathrm{Fe}_{2} \mathrm{O}_{3}-\mathrm{SiO}_{2}$ and $\mathrm{Dy}_{2} \mathrm{O}_{3}-\mathrm{SiO}_{2}$ Composites Produced by a Facile Method
}

\author{
ESRA KENDIR (1), ${ }^{1,2,4}$ ATAKAN TEKGÜL, ${ }^{3}$ İLKER KÜÇÜK, ${ }^{3}$ \\ and ŞERAFETTIN YALTKAYA ${ }^{1}$ \\ 1.-Physics Department, Akdeniz University, 07058 Antalya, Turkey. 2.-Present address: \\ National Nanotechnology Research Center, Bilkent University, 06800 Ankara, Turkey. \\ 3.-Physics Department, Science and Literature Faculty, Uludag University, 16059 Bursa, \\ Turkey. 4.—e-mail: fiz.esrakendir@gmail.com
}

We prepared $\mathrm{SiO}_{2}, \mathrm{Fe}_{2} \mathrm{O}_{3}-\mathrm{SiO}_{2}$, and $\mathrm{Dy}_{2} \mathrm{O}_{3}-\mathrm{SiO}_{2}$ composites by an enhanced method and reported the result of their structural, optical and magnetic properties. In the x-ray diffraction results of the $\mathrm{Fe}_{2} \mathrm{O}_{3}-\mathrm{SiO}_{2}, \mathrm{Fe}_{2} \mathrm{O}_{3}$ and the $\mathrm{SiO}_{2}$ it is evident that these composites are crystallized in rhombohedral and trigonal structures, respectively. In the $\mathrm{Dy}_{2} \mathrm{O}_{3}-\mathrm{SiO}_{2}$ composite, $\mathrm{SiO}_{2}$ transforms into a trigonal structure with the addition of Dy. The absorption bands belong to $\mathrm{Fe}_{2} \mathrm{O}_{3}$, and $\mathrm{Dy}_{2} \mathrm{O}_{3}$ were obtained using the Fourier transform infrared spectra. In ultraviolet-visible spectra, the photocatalytic properties of $\mathrm{Fe}_{2} \mathrm{O}_{3}-\mathrm{SiO}_{2}$ and $\mathrm{Dy}_{2} \mathrm{O}_{3}-\mathrm{SiO}_{2}$ were determined as a function of time at room temperature. Maximum transmittance change at $800 \mathrm{~nm}$ was $75 \%$ and $40 \%$ for composites $\mathrm{Fe}_{2} \mathrm{O}_{3}-\mathrm{SiO}_{2}$, and $\mathrm{Dy}_{2} \mathrm{O}_{3}-\mathrm{SiO}_{2}$, respectively. The photocatalytic property of $\mathrm{Dy}_{2} \mathrm{O}_{3}-\mathrm{SiO}_{2}$ composite increases gradually from short to long in the wavelength region where it exhibits a maximum value in the visible region. In magnetic measurements, a weak ferromagnetic behavior was observed in the $\mathrm{Fe}_{2} \mathrm{O}_{3}-\mathrm{SiO}_{2}$, while $\mathrm{Dy}_{2} \mathrm{O}_{3}-\mathrm{SiO}_{2}$ exhibited paramagnetic behavior as expected. The saturation and coercivity values for $\mathrm{Fe}_{2} \mathrm{O}_{3}-\mathrm{SiO}_{2}$ were found to be $0.15 \mathrm{Am}^{2} \mathrm{~kg}^{-1}$ and $40 \mathrm{mT}$, respectively.

Key words: Silica, $\mathrm{Fe}_{2} \mathrm{O}_{3}-\mathrm{SiO}_{2}, \mathrm{Dy}_{2} \mathrm{O}_{3}-\mathrm{SiO}_{2}$, optical properties

\section{INTRODUCTION}

Composite materials are widely used in various applications in industry such as filtration in wastewater treatment, ${ }^{1}$ biotechnology/biomedicine, ${ }^{2,3}$ magnetic paper, ${ }^{4}$ and catalysis. ${ }^{5,6}$ Microand nano-scale silica and silicon dioxide particles are important for these composite materials because of the ease of preparation and ability to control the size, a high surface-to-volume ratio, and bio-compatibility. ${ }^{2}$ As an example, silicon dioxide is used with photocatalytic materials. In the presence of light, the catalytic property of a material is referred by the photocatalyst property, and here the photocatalyst provides an increase in the rate of chemical

(Received July 10, 2019; accepted October 4, 2019; published online October 23, 2019) radiation by activating a catalyst by ultraviolet (UV) or visible light. ${ }^{7}$ Here, the light causes electrons and holes in the photocatalytic reaction. The catalysts are semiconductor materials such as $\mathrm{TiO}_{2}$ and $\mathrm{Fe}_{2} \mathrm{O}_{3}$, so an electron transfers from the valance band to the conduction band with the absorption of the light.

To develop new composite materials, many studies are carried out. ${ }^{8-17}$ There are many techniques to improve the unique properties of the materials such as surface modification, formation of composites, doping with different materials such as rare earth metals, and different production methods. ${ }^{7}$ Synthesis and investigation of these new materials are still interesting for researchers. Zinatloo-Ajabshir et al. ${ }^{18}$ presented the $\mathrm{Dy}_{2} \mathrm{Sn}_{2} \mathrm{O}_{7}-\mathrm{SnO}_{2}$ with a simple, cost-effective, convenient, and eco-friendly method and compared with $\mathrm{SnO}_{2}$. They found better photocatalytic performance in the $\mathrm{Dy}_{2} \mathrm{Sn}_{2} \mathrm{O}_{7}-\mathrm{SnO}_{2}$ 
than in $\mathrm{SnO}_{2}$ alone. Mahdiani et al. ${ }^{19}$ investigated a new nanostructure, $\mathrm{CuFe}_{12} \mathrm{O}_{19} / \mathrm{CNT}$ (carbon nanotube) and $\mathrm{CuFe}_{12} \mathrm{O}_{19}$ /graphene and reported that the graphene-based nanocomposites led to increasing the photocatalytic activity under UV irradiation. The relation between the photocatalytic materials and the materials with large surface area and high porosity such as $\mathrm{SiO}_{2}$ and graphene is essential to increase the photocatalytic property. ${ }^{1,19}$

$\mathrm{Fe}_{2} \mathrm{O}_{3}$ nano- and microparticles are of interest for various applications in industry as catalysts, gas sensors, pigments, photo-anodes in photo-electrochemical cells or contrast agents in magnetic resonance imaging because of their hardness, catalytic activity, and surface resistivity, as well as magnetic, optical, and electronic properties. ${ }^{5,6}$ Because of these unique properties, $\mathrm{Fe}_{2} \mathrm{O}_{3}$ has been combined to produce a composite structure with $\mathrm{SiO}_{2}$ that has a large surface area and high porosity particles. ${ }^{20,21}$ Bogatrev et al. ${ }^{21}$ investigated the $\mathrm{Fe}_{2} \mathrm{O}_{3} / \mathrm{SiO}_{2}$ nanocomposite produced by chemical reaction, and they showed that the reaction and treatment conditions allow the production of this nanocomposite of a high specific surface area that can be of importance for practical applications. Balbuena et al. ${ }^{20}$ reported the $\alpha-\mathrm{Fe}_{2} \mathrm{O}_{3} / \mathrm{SiO}_{2}$ composites for enhanced photocatalytic NO oxidation. In the studies of $\mathrm{Fe}$ or $\mathrm{Fe}_{2} \mathrm{O}_{3} / \mathrm{TiO}_{2}$ composites, $\mathrm{Fe}^{4+}$ ions are reduced to $\mathrm{Fe}^{3+}$ by the photochemical reactions. Therefore, the composites absorb the photons, according to transformation of all $\mathrm{Fe}^{4+}$ to $\mathrm{Fe}^{3+}$ ions. ${ }^{22,23}$ The rare earth element, $\mathrm{Dy}^{3+}$ ion, is identified as an active luminescence center and also as $f$-localized trap-creating ion. ${ }^{24,25}$ When the $d$ orbitals of rare earth elements are excited by the UV light, the $d-f$ transition occurs because of the absorption of photons. As a result, the rare earth elements emit the light to return the initial state. The rare earth elements are generally used in various fields such as in preparing light-emitting diodes, optical fibers, amplifiers and biomedicine for its optical characteristics and its luminescence emission capabilities. Therefore, this property can be utilized for the preparation of a photocatalyst by rare earth or rare earth oxides onto oxides such as $\mathrm{SiO}_{2}$ andTiO ${ }_{2}$. In the previous studies, ${ }^{26-28} \mathrm{Dy}_{2} \mathrm{O}_{3}$ has been doped on $\mathrm{ZnO}$ and studied for various applications other than photocatalysis induced by UV light irradiation.

In this study, we prepared the $\alpha-\mathrm{Fe}_{2} \mathrm{O}_{3}-\mathrm{SiO}_{2}$ and $\mathrm{Dy}_{2} \mathrm{O}_{3}-\mathrm{SiO}_{2}$ composites by a facile method. In the preparation of the composites, various methods are used, such as chemical reaction and sol-gel. The preparation of these is difficult, and the contamination risk is high. As an example, sol-gel method is used in the most of study; however, this technique cannot achieve its full industrial potential due to some limitations such high permeability, weak bonding, and hard porosity control. ${ }^{29}$ The sol-gel process uses several steps such as mixing and casting, and many chemical reactions take place in the formation of metal alkoxide particles to a composite in these steps. Also, the residual precursor must be burned to remove the organic materials produced in the chemical reactions, and the burning temperature plays a crucial role in the purity of the final composite. Lack of scientific understanding of these complex reactions is a major drawback of the sol-gel technique. ${ }^{29,30}$ The morphological and structural analysis was performed by x-ray diffraction (XRD) and scanning electron microscopy (SEM) at room temperature. The optical properties were measured by Fourier transform infrared (FTIR) spectrometry in the range of $400-4000 \mathrm{~cm}^{-1}$ and ultraviolet-visible (UV-Vis) spectrometry between $200 \mathrm{~nm}$ and $800 \mathrm{~nm}$. Also, the magnetic behavior of these composites was investigated by hysteresis curves under $2 \mathrm{~T}$ at room temperature.

\section{EXPERIMENTAL}

\section{Synthesis of Composites}

$\mathrm{SiO}_{2}, \mathrm{Fe}_{2} \mathrm{O}_{3}-\mathrm{SiO}_{2}$, and $\mathrm{Dy}_{2} \mathrm{O}_{3}-\mathrm{SiO}_{2}$ composites were prepared with a heat-treatment process by using a high-temperature atmosphere oven. Five grams of pure Si powder (99.99\%) was placed in an atmospheric oven with an alumina combustion boat and heated for 5 days at $1673 \mathrm{~K}$. The powder was manually mixed once a day. The color of the powder changed from gray to blue throughout the process.

For $\mathrm{Fe}_{2} \mathrm{O}_{3}-\mathrm{SiO}_{2}$ and $\mathrm{Dy}_{2} \mathrm{O}_{3}-\mathrm{SiO}_{2}$ composites, pure $\mathrm{Fe}(99.9 \%)$ and pure Dy $(99.9 \%)$ powder were separately mixed with $\mathrm{SiO}_{2}$ powders produced in the initial process. The mixed ratio is 1:4 (pure Fe: $\mathrm{SiO}_{2}$ and pure $\mathrm{Dy}: \mathrm{SiO}_{2}$ ) and total powder weight is $2 \mathrm{~g}$ for each composite. The same heating ( $1673 \mathrm{~K}$ for 5 days) and mixing processes were applied on prepared samples. All composites were slowly cooled to room temperature in the oven.

\section{Structural, Morphological and Magnetic Characterizations}

The structural analyses were performed by x-ray diffraction (XRD). The patterns were collected at room temperature in the range of $20^{\circ}<2 \theta<75^{\circ}$ using $\mathrm{Cu} \mathrm{K} \mathrm{K}_{\alpha}$ radiation. Their crystal lattice and parameters were determined by FullProf and QUALX $2^{31}$ software. Moreover, the morphological analysis was conducted by scanning electron microscopy with energy dispersive x-ray (SEM-EDX). The field dependencies of the magnetization curves, $M(H)$, were measured by a vibrating sample magnetometer (Microsense EZ9).

\section{Optical Characterization}

The UV-Visible and FT-IR analyses of the powder samples were carried out using a potassium bromide $(\mathrm{KBr})$ pellet. The vibration states of the samples were characterized by FTIR spectra, which 
was taken at room temperature using the $\mathrm{KBr}$ disc. Spectra in the wave-number range between $400 \mathrm{~cm}^{-1}$ and $4000 \mathrm{~cm}^{-1}$ were obtained. The dark current noises and background were corrected in the infrared spectrum using two-point baseline correction.

The UV-Visible transmittance spectrum measurements were performed at a wavelength range of 200-800 nm. Cary 5000 UV-Vis-NIR spectrophotometer was used for recording the spectra with $1 \mathrm{~nm}$ resolution.

\section{RESULTS AND DISCUSSION}

Figure $1 \mathrm{a}, \mathrm{b}$ and $\mathrm{c}$ shows the refined XRD patterns of $\mathrm{SiO}_{2}, \mathrm{Fe}_{2} \mathrm{O}_{3}-\mathrm{SiO}_{2}$ and $\mathrm{Dy}_{2} \mathrm{O}_{3}-\mathrm{SiO}_{2}$ composites at room temperature. The pattern of $\mathrm{SiO}_{2}$ shows

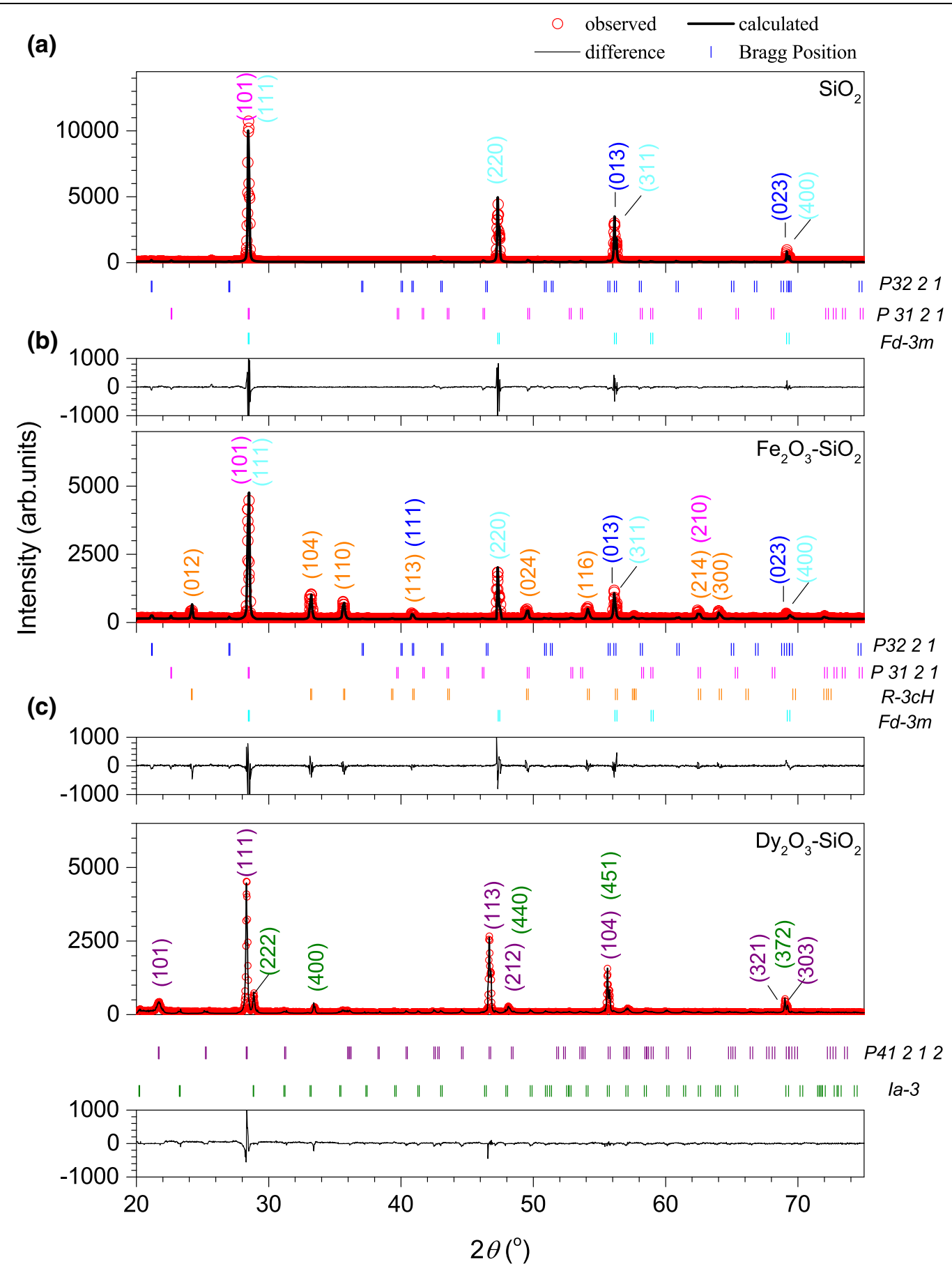

Fig. 1. Rietveld refinement results. Observed (red circles) and calculated (black lines) intensities of $X R D$ patterns (a) $\mathrm{SiO}_{2}(\mathrm{~b}) \mathrm{Fe}_{2} \mathrm{O}_{3}-\mathrm{SiO}_{2}$ (c) $\mathrm{Dy}_{2} \mathrm{O}_{3}-\mathrm{SiO}_{2}$. Thin lines in the lower part of each plot show the difference between the calculated and observed patterns. The vertical bars refer to the calculated allowed Bragg reflections. Here, P32 21 and $P 3121$ are the trigonal, $F d-3 m$ and $l a-3$ are the cubic, $R-3 c H$ is the rhombohedral and P41 212 is the tetragonal (Color figure online). 
Table I. Crystallographic data for the structural refinement

\begin{tabular}{|c|c|c|c|c|c|}
\hline Sample & Phases & Crystal system & Space group & $a=b(\AA)$ & $c(\AA)$ \\
\hline \multirow[t]{3}{*}{$\mathrm{SiO}_{2}$} & $\mathrm{SiO}_{2}(1)$ & Trigonal & P32 21 & 4.853 & 5.332 \\
\hline & $\mathrm{SiO}_{2}(2)$ & Trigonal & $P 3121$ & 4.535 & 5.204 \\
\hline & $\mathrm{Si}$ & Cubic & $F d-3 m$ & 5.430 & $=a$ \\
\hline \multirow[t]{4}{*}{$\mathrm{Fe}_{2} \mathrm{O}_{3}-\mathrm{SiO}_{2}$} & $\mathrm{Fe}_{2} \mathrm{O}_{3}$ & Rhombohedral & $R-3 c H$ & 5.032 & 13.749 \\
\hline & $\mathrm{SiO}_{2}(1)$ & Trigonal & P32 21 & 4.847 & 5.338 \\
\hline & $\mathrm{SiO}_{2}(2)$ & Trigonal & $P 3121$ & 4.539 & 5.193 \\
\hline & $\mathrm{Si}$ & Cubic & $F d-3 m$ & 5.427 & $=a$ \\
\hline \multirow[t]{2}{*}{$\mathrm{Dy}_{2} \mathrm{O}_{3}-\mathrm{SiO}_{2}$} & $\mathrm{Dy}_{2} \mathrm{O}_{3}$ & Tetragonal & $P 41212$ & 4.991 & 6.994 \\
\hline & $\mathrm{SiO}_{2}$ & Cubic & $I a-3$ & 10.658 & $=a$ \\
\hline
\end{tabular}

the mixed phases of $\mathrm{SiO}_{2}$ (trigonal) and of $\mathrm{Si}$ (cubic). Fe doped $\mathrm{SiO}_{2}$ composite exhibits a similar crystal structure for $\mathrm{SiO}_{2}$ and a rhombohedral structure related to $\mathrm{Fe}_{2} \mathrm{O}_{3}$ in Fig. 1b. When Dy is added to $\mathrm{SiO}_{2}$, the obtained composite includes two phases that correspond to $\mathrm{Dy}_{2} \mathrm{O}_{3}$ and $\mathrm{SiO}_{2}$ respectively, as seen in Fig. 1c. Here, the crystal structure of $\mathrm{SiO}_{2}$ changes from trigonal to cubic due to the addition of Dy content. A similar result has been shown in the study of Vasanthavel et al. ${ }^{32}$ where the addition of Dy to the $\mathrm{ZrO}_{2}-\mathrm{SiO}_{2}$, transforms the structure of composition from tetragonal to cubic. The XRD result of the $\mathrm{Dy}_{2} \mathrm{O}_{3}-\mathrm{SiO}_{2}$ indicates that the $\mathrm{SiO}_{2}$ crystallizes in the cubic form, and this may be caused by the Dy addition as seen in Ref. 32 . Consequently, the obtained crystal structures of the composites prove that the synthesis explained herein can be employed as an alternative preparation procedure. The crystal structures and calculated lattice parameters of the patterns are given in Table I. The results show that the expected composite materials were obtained.

The morphology of $\mathrm{SiO}_{2}, \mathrm{Fe}_{2} \mathrm{O}_{3}-\mathrm{SiO}_{2}$, and $\mathrm{Dy}_{2} \mathrm{O}_{3}$ $\mathrm{SiO}_{2}$ were investigated by SEM. The measurements were performed at $15 \mathrm{kV}$. The SEM images are given in Fig. $2 \mathrm{a}, \mathrm{b}$ and c. Figure $2 \mathrm{a}$ shows the $\mathrm{SiO}_{2}$ sample, and the micro particles integrated each other with heat treatment. The $\mathrm{Fe}_{2} \mathrm{O}_{3}$ particles congregate regionally in Fig. $2 \mathrm{~b}$ and they have a spherical form as seen in the inset of Fig. $2 b$. In the $\mathrm{Dy}_{2} \mathrm{O}_{3}-\mathrm{SiO}_{2}$ (Fig. 2c), the particle sizes are close to each other, and the $\mathrm{SiO}_{2}$ particles form soft-edged structure. The EDX measurements are performed, and the indicated points are shown in the figures. The EDX spectra are also plotted in Fig. 2. In the spectra, the Si, Fe and Dy peaks were clearly determined. The results show that the expected composites were obtained.

FTIR absorption spectral curves of $\mathrm{Si}, \mathrm{SiO}_{2}$, $\mathrm{Fe}_{2} \mathrm{O}_{3}-\mathrm{SiO}_{2}$, and $\mathrm{Dy}_{2} \mathrm{O}_{3}-\mathrm{SiO}_{2}$ are presented in Fig. 3. The FTIR absorption spectrum of Si sample (black line) has main four absorption bands at around $1380 \mathrm{~cm}^{-1}, 1637 \mathrm{~cm}^{-1}, 3446 \mathrm{~cm}^{-1}$ and 3735 $\mathrm{cm}^{-1}$. The peak at $3735 \mathrm{~cm}^{-1}$ is due to the nonhydrogen-bonded silanol. At $1637 \mathrm{~cm}^{-1}$ and 3446 $\mathrm{cm}^{-1}$, the absorption peaks are attributed to stretching modes of the absorbed water molecule. ${ }^{33,34}$ It is known that the symmetric and anti- symmetric stretching modes of the $\mathrm{Si}-\mathrm{O}-\mathrm{Si}$ bonds are IR active in $800-1300 \mathrm{~cm}^{-1}$ region. ${ }^{35-38}$ In the $\mathrm{SiO}_{2}$ sample (red line), the additional peaks at $2356 \mathrm{~cm}^{-1}, 2333 \mathrm{~cm}^{-1}, 1093 \mathrm{~cm}^{-1}, 786 \mathrm{~cm}^{-1}$, and $478 \mathrm{~cm}^{-1}$ were observed. The $1380 \mathrm{~cm}^{-1}, 2356 \mathrm{~cm}^{-1}$ and $2333 \mathrm{~cm}^{-1}$ peaks are attributed to $\mathrm{CO}_{2}$ in the air. $^{39,40}$ The weak absorption peak at 786 and the medium absorption peak at $478 \mathrm{~cm}^{-1}$ are due to symmetric stretching vibrations and bending vibrations of Si-O-Si, respectively. ${ }^{41}$

In the FTIR spectrum of $\mathrm{Fe}_{2} \mathrm{O}_{3}-\mathrm{SiO}_{2}$ composite (blue line), the new additional peaks were found at $1128 \mathrm{~cm}^{-1}, 1033 \mathrm{~cm}^{-1}$ and $586 \mathrm{~cm}^{-1}$. The peaks at $1033 \mathrm{~cm}^{-1}$ and $1093 \mathrm{~cm}^{-1}$ partially overlap with each other. The peak at $1128 \mathrm{~cm}^{-1}$ is due to asymmetric stretching bonds of Si-O-Si. The peaks at $1033 \mathrm{~cm}^{-1}$ and $586 \mathrm{~cm}^{-1}$ are an indication of the presence of Si-O-Fe. ${ }^{42}$

$\mathrm{Dy}_{2} \mathrm{O}_{3}-\mathrm{SiO}_{2}$ (cyan line) composite exhibits the peaks at $1128 \mathrm{~cm}^{-1}, \quad 1093 \mathrm{~cm}^{-1}, \quad 786 \mathrm{~cm}^{-1}$, $613 \mathrm{~cm}^{-1}$ and $516 \mathrm{~cm}^{-1}$ in its FTIR spectrum and here, the peaks at $1128 \mathrm{~cm}^{-1}, 1093 \mathrm{~cm}^{-1}, 786 \mathrm{~cm}^{-1}$ appear stronger than the other composites, and this may be caused by the structural change of $\mathrm{SiO}_{2}$ since $\mathrm{SiO}_{2}$ undergoes a trigonal to cubic transition with the addition of Dy content. Also, the peaks at $613 \mathrm{~cm}^{-1}$ and $516 \mathrm{~cm}^{-1}$ are due to Dy. The peaks at $586 \mathrm{~cm}^{-1}$ and $1033 \mathrm{~cm}^{-1}$ disappear in this composite. This situation indicates that these peaks are associated with the existence of $\mathrm{Fe}_{2} \mathrm{O}_{3}$.

UV-Visible absorption spectroscopy is a useful technique to explore the optical properties of semiconducting micro and nanoparticles. ${ }^{43,44}$ The transmittance measurements of $\mathrm{SiO}_{2}, \mathrm{Fe}_{2} \mathrm{O}_{3}-\mathrm{SiO}_{2}$, and $\mathrm{Dy}_{2} \mathrm{O}_{3}-\mathrm{SiO}_{2}$ were performed between $200 \mathrm{~nm}$ and $800 \mathrm{~nm}$ wavelengths.

The transmittance spectrum of $\mathrm{SiO}_{2}$ at room temperature is given in Fig. 4a. The transmittance slowly increases up to wavelength $500 \mathrm{~nm}$ and then rapidly continues to grow until reaching a maximum at $800 \mathrm{~nm}$. Here, the absorbance of the long wavelength in this sample is higher than the short wavelength. The spectra were measured as a function of time and generally, the obtained curves overlapped with each other. Therefore, the other curves are not given in the figure. 

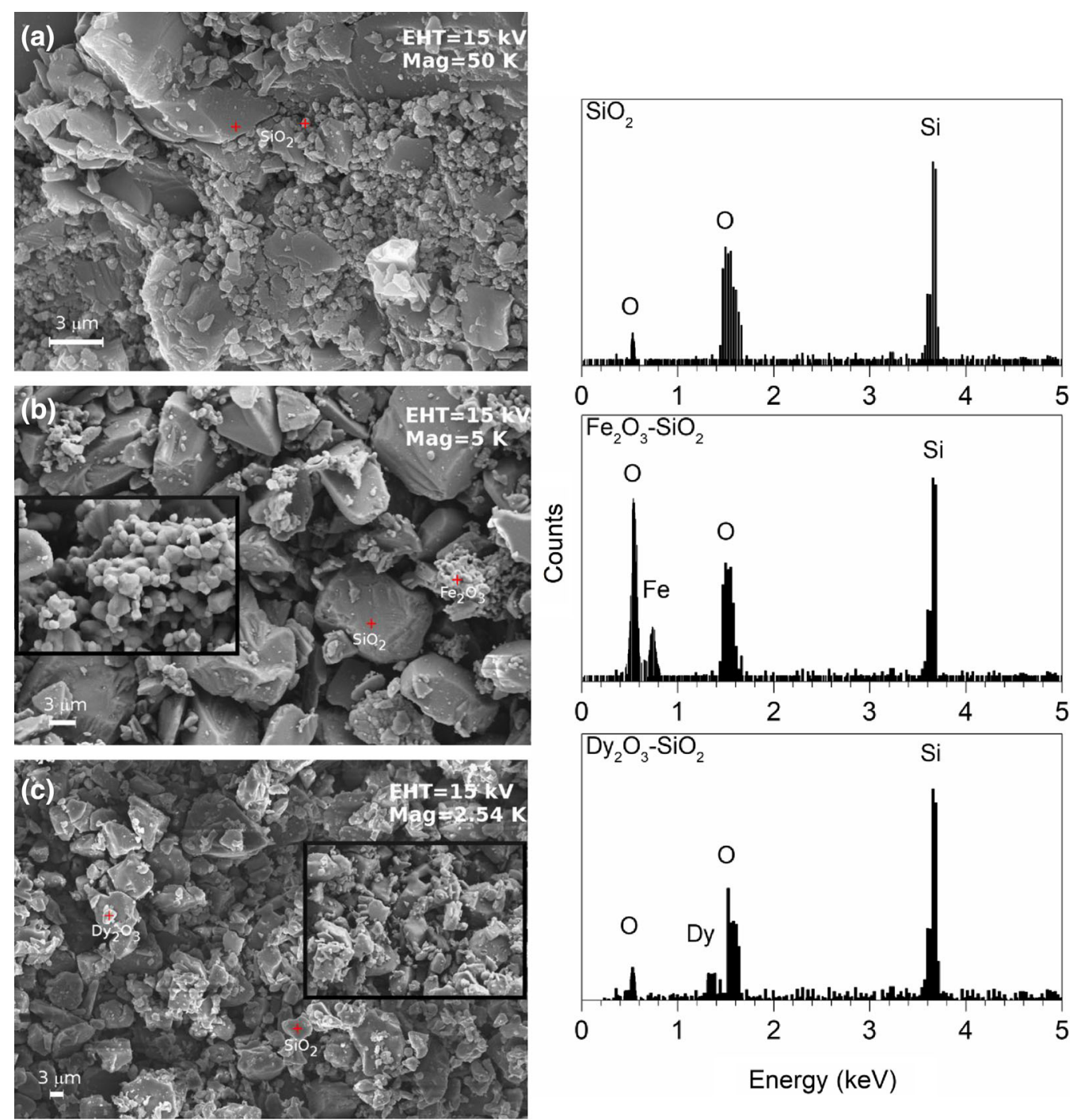

Fig. 2. SEM images and EDX spectra of (a) $\mathrm{SiO}_{2}$ (b) $\mathrm{Fe}_{2} \mathrm{O}_{3}-\mathrm{SiO}_{2}$ (c) $\mathrm{Dy}_{2} \mathrm{O}_{3}-\mathrm{SiO}_{2}$ samples.

UV-Vis measurement of the $\mathrm{Fe}_{2} \mathrm{O}_{3}-\mathrm{SiO}_{2}$ was performed with respect to time, and the variation of its transmittance curves are given in Fig. 4b. The transmittance in the range of $200-425 \mathrm{~nm}$ is lower than $20 \%$. Between $425 \mathrm{~nm}$ and $800 \mathrm{~nm}$, it decreases from $100 \%$ to $25 \%$ as a function of time. Here, the absorbance of the sample is increased due to the electrons movements in $s$ and $d$ orbitals of $\mathrm{Fe}$ when it is exposed to light. In the $\mathrm{Fe}_{2} \mathrm{O}_{3}, \mathrm{Fe}^{3+}$ ions are a better electron scavenger than $\mathrm{O}_{2}, 22$ and therefore, the oxidation of $\mathrm{Fe}^{3+} \rightarrow \mathrm{Fe}^{4+}$ can occur. The photocatalytic property of this composite increases step by step the wavelength increases and it exhibits a maximum in the visible region. The variation amount of the transmittance at 425 and $800 \mathrm{~nm}$ are given in Fig. 4c. At $425 \mathrm{~nm}$, the variation is close to zero; however, a remarkable $60 \%$ variation occurs within $200 \mathrm{~s}$ at 800 $\mathrm{nm}$. Moreover, the $y=y=y_{0}+A \exp \left(R_{0} x\right)$ fit function was applied to these variations, and parameter A changed from - 4.67 to 114.69 .
The transmittance measurements of $\mathrm{Dy}_{2} \mathrm{O}_{3}-\mathrm{SiO}_{2}$ sample are plotted in Fig. $4 \mathrm{~d}$. As observed in the $\mathrm{Fe}_{2} \mathrm{O}_{3}-\mathrm{SiO}_{2}$, the photocatalytic property was found, but in this sample, the variation occurred in the range of $425-800 \mathrm{~nm}$. The transmittance in the range of $200-425 \mathrm{~nm}$ is about $35 \%$. Between $425 \mathrm{~nm}$ and $800 \mathrm{~nm}$, it decreases from $100 \%$ to $60 \%$ due to time. Fig. 4e shows the change percentage for transmittance at 425 and $800 \mathrm{~nm}$. At $800 \mathrm{~nm}$, the $30 \%$ variation occurs within $300 \mathrm{~s}$. When these variations are fitted with the same function, the parameter A changed from 5.37 to 62.31 . In the wide range in the UV region, the absorbance of the sample increases with respect to time. Moreover, the absorbance of the short wavelengths in the UV region begins to increase with Dy content. This behavior is caused by $d$ and $f$ orbitals of Dy, and here, the electrons are exposed by the light. Also, $\mathrm{Dy}^{3+}$ ions oxidate to $\mathrm{Dy}^{4+}$. The absorbance of the sample increases in between $\mathrm{nm} 500$ and $800 \mathrm{~nm}$. 


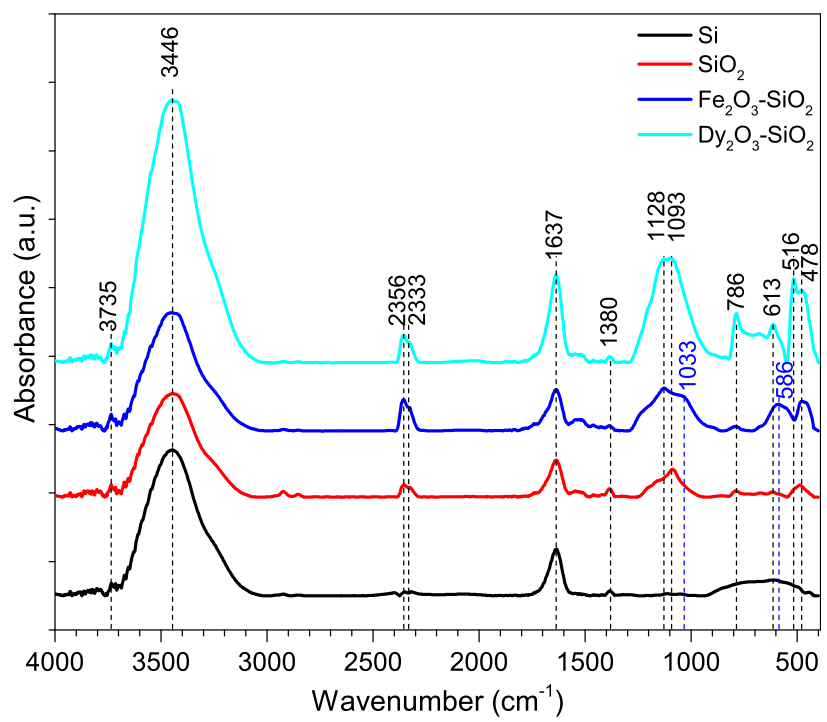

Fig. 3. The FTIR spectra of $\mathrm{Si}$ (black), $\mathrm{SiO}_{2}$ (red), $\mathrm{Fe}_{2} \mathrm{O}_{3}-\mathrm{SiO}_{2}$ (blue) and $\mathrm{Dy}_{2} \mathrm{O}_{3}-\mathrm{SiO}_{2}$ (cyan) (Color figure online).
This increase could be due to the presence of color centers. $^{45}$ On the other hand, the change of absorbance is lower than the Fe doped sample, but the absorbance of the light occurs at the wide range wavelength.

To check the performance of the $\mathrm{Fe}_{2} \mathrm{O}_{3}-\mathrm{SiO}_{2}$ and $\mathrm{Dy}_{2} \mathrm{O}_{3}-\mathrm{SiO}_{2}$, the sample was left for $30 \mathrm{~min}$ inside the spectrometer in the dark, and a new measurement was performed shown in Fig. 5a and b. Here, the dash lines indicate the first and last measurements taken from Fig. 4.b and the straight lines show the new measurements. As seen in the figure, the absorbed light causes an increase at the transmittance in the $200-750 \mathrm{~nm}$ wavelength region in the new measurements. This shows that in the dark, the new absorbed light could trigger the change in the short wavelength and the absorbed light from the initial measurement may not emit out of the sample. The absorbed light causes the color centers to occur in the composite. These are due to

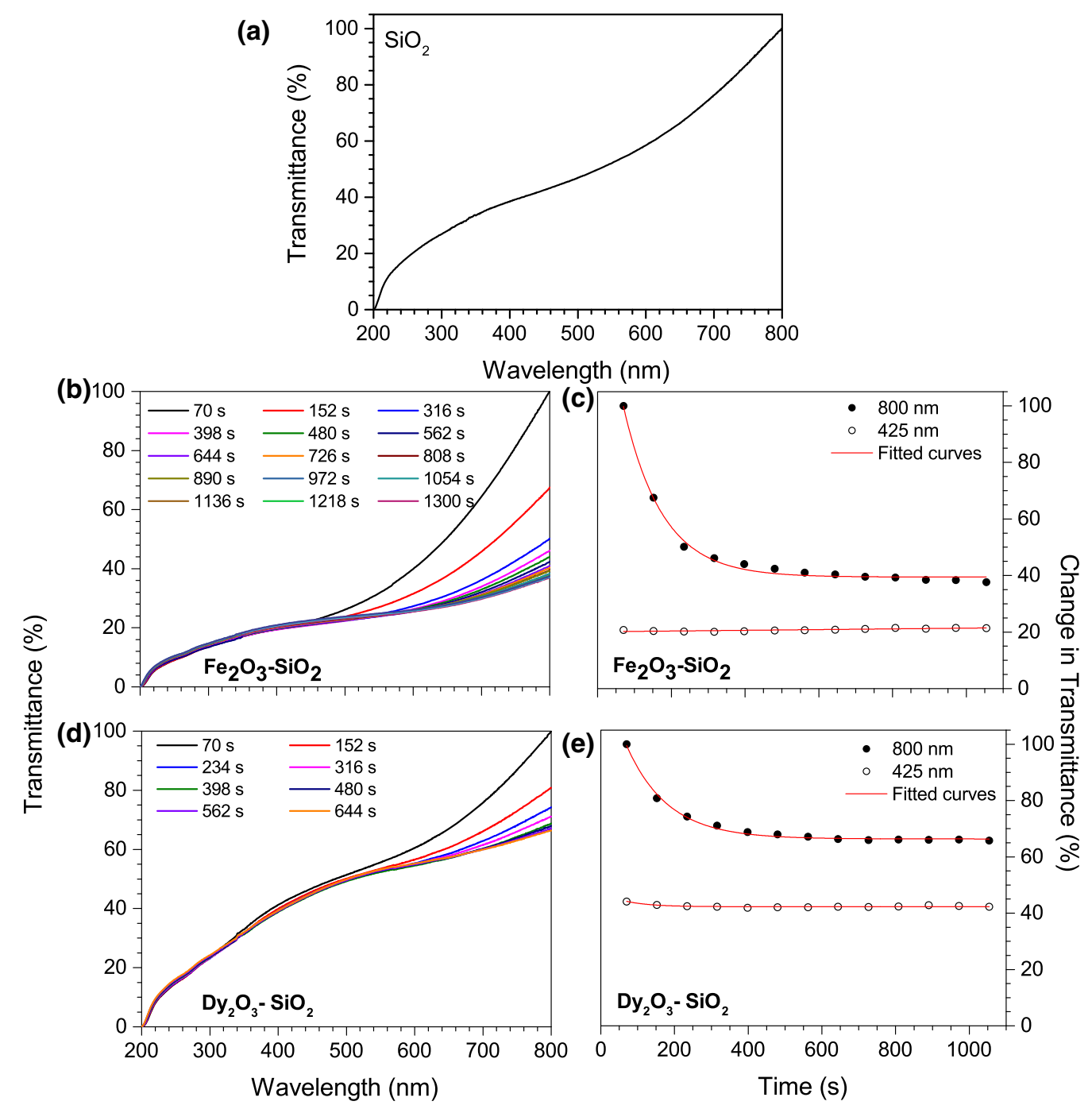

Fig. 4. At room temperature, the UV-Vis spectra depending on time of (a) $\mathrm{SiO}_{2}$ (b) $\mathrm{Fe}_{2} \mathrm{O}_{3}-\mathrm{SiO}_{2}$ (d) $\mathrm{Dy}_{2} \mathrm{O}_{3}-\mathrm{SiO}_{2}$ and the variation of transmittance at 425 and $800 \mathrm{~nm}$ wavelength for (c) $\mathrm{Fe}_{2} \mathrm{O}_{3}-\mathrm{SiO}_{2}$, (e) $\mathrm{Dy}_{2} \mathrm{O}_{3}-\mathrm{SiO}_{2}$. 


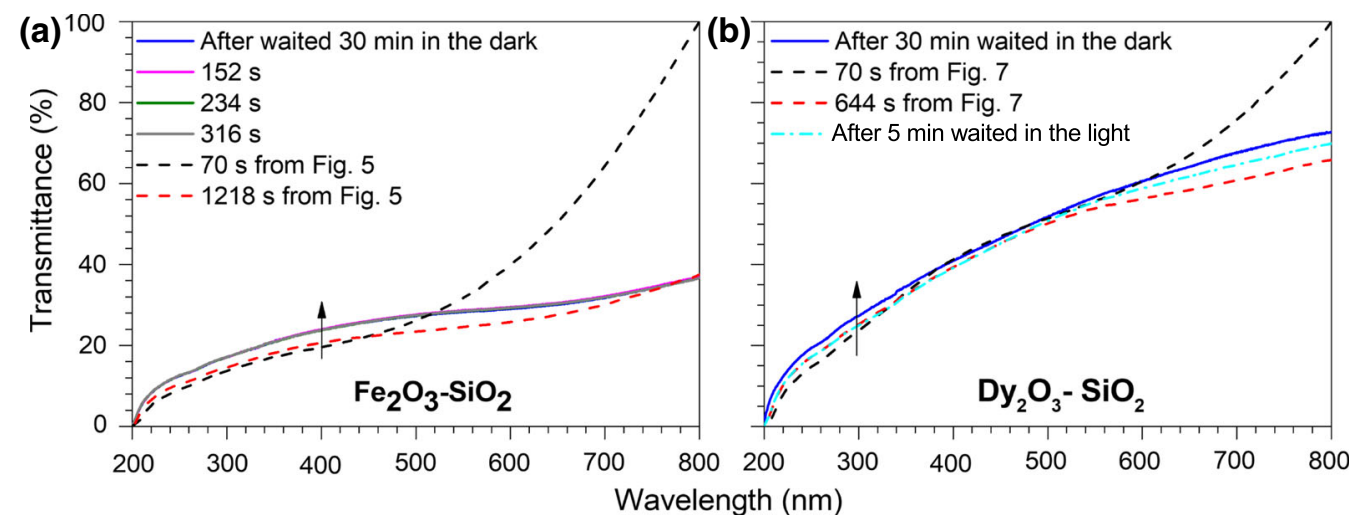

Fig. 5. After $30 \mathrm{~min}$ in the dark, the UV-Vis spectrum of (a) $\mathrm{Fe}_{2} \mathrm{O}_{3}-\mathrm{SiO}_{2}$ (b) $\mathrm{Dy}_{2} \mathrm{O}_{3}-\mathrm{SiO}_{2}$.

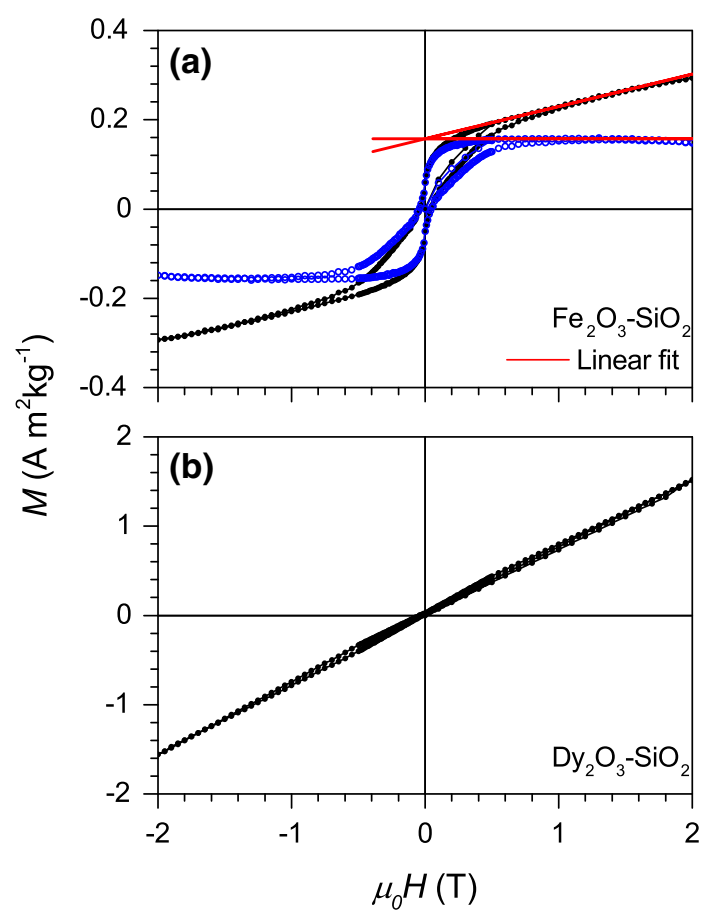

Fig. 6. Hysteresis curves of (a) $\mathrm{Fe}_{2} \mathrm{O}_{3}-\mathrm{SiO}_{2}$. The black line with dots is the measured data and the blue line with hallow circle is the obtained data after the removed paramagnetic part. The red line is the fit curves and (b) the paramagnetic curve of $\mathrm{Dy}_{2} \mathrm{O}_{3}-\mathrm{SiO}_{2}$ under 2 $\mathrm{T}$ magnetic field at room temperature (Color figure online).

the electron and hole trapping in the $\mathrm{Fe}^{3+}$ and $\mathrm{Fe}^{4+}$ ions. As a result of this, these color centers might be permanent after the initial irradiation. ${ }^{46}$

Similarly, the $\mathrm{Dy}_{2} \mathrm{O}_{3}-\mathrm{SiO}_{2}$ sample waited in the dark for $30 \mathrm{~min}$ and in the light for $5 \mathrm{~min}$, separately. In Fig. 5b, the dash lines indicate the first and last lines from initial measurements in Fig. 4d. The transmittance increases a bit more between $200 \mathrm{~nm}$ and $800 \mathrm{~nm}$, but this change is more prominent than other regions between $500 \mathrm{~nm}$ and $800 \mathrm{~nm}$. This shows that the sample emits the absorbed light in the initial state and, therefore, it recovers in the dark. However, when the sample is exposed to light for $5 \mathrm{~min}$, the absorption begins between $550 \mathrm{~nm}$ and $800 \mathrm{~nm}$ wavelength.

It is very well known that the transition element, Fe exhibits strongly magnetic behavior and moreover, iron oxides have both magnetic property and high coercivity due to their hysteresis. ${ }^{47,48}$ In Fig. $6 \mathrm{a}$ and $\mathrm{b}$, the hysteresis curves of $\mathrm{Fe}_{2} \mathrm{O}_{3}-\mathrm{SiO}_{2}$ and $\mathrm{Dy}_{2} \mathrm{O}_{3}-\mathrm{SiO}_{2}$ composites are given under $2 \mathrm{~T}$ magnetic field at room temperature. In Fig. 6a, the magnetic behavior of the $\mathrm{Fe}_{2} \mathrm{O}_{3}-\mathrm{SiO}_{2}$ is a mixture of paramagnetic behavior related to $\mathrm{SiO}_{2}$ and the ferromagnetic behavior related to $\mathrm{Fe}_{2} \mathrm{O}_{3}$. To obtain the ferromagnetic part of this curve, the linear fit function was applied, and it was removed from this curve. The saturation value for $\mathrm{Fe}_{2} \mathrm{O}_{3}-\mathrm{SiO}_{2}$ was found to be $0.15 \mathrm{Am}^{2} \mathrm{~kg}^{-1}$. The obtained coercivity of the sample is $40 \mathrm{mT}$. In Fig. 6b, the $\mathrm{Dy}_{2} \mathrm{O}_{3}-\mathrm{SiO}_{2}$ shows the paramagnetic behavior at room temperature. Here, both $\mathrm{Dy}_{2} \mathrm{O}_{3}$ and $\mathrm{SiO}_{2}$ are the paramagnetic and $\mathrm{Dy}_{2} \mathrm{O}_{3}$ exhibits ferromagnetic behavior at low temperature. ${ }^{49,50}$

\section{CONCLUSION}

In this work, $\mathrm{SiO}_{2}, \mathrm{Fe}_{2} \mathrm{O}_{3}-\mathrm{SiO}_{2}$, and $\mathrm{Dy}_{2} \mathrm{O}_{3}-\mathrm{SiO}_{2}$ composites were prepared by a facile method and their structural, optical and magnetic properties were investigated. The XRD results show that the expected composites have been prepared successfully. The $\mathrm{SiO}_{2}$ crystallizes in a mixture of two trigonal crystal structures and $\mathrm{Fe}_{2} \mathrm{O}_{3}-\mathrm{SiO}_{2}$ possesses a mixture of rhombohedral (related to $\mathrm{Fe}_{2} \mathrm{O}_{3}$ ) and trigonal (related to $\mathrm{SiO}_{2}$ ) crystal structures. For $\mathrm{Dy}_{2} \mathrm{O}_{3}-\mathrm{SiO}_{2}$ composite, the crystal structure is found to have a mixture of tetragonal $\mathrm{Dy}_{2} \mathrm{O}_{3}$ and cubic $\mathrm{SiO}_{2}$. The $\mathrm{SiO}_{2}$ transforms from trigonal to cubic with the addition of Dy. In the FTIR spectra, the absorption bands were determined at room temperature for all composites. The peaks at $1033 \mathrm{~cm}^{-1}$ and $586 \mathrm{~cm}^{-1}$ due to $\mathrm{Fe}_{2} \mathrm{O}_{3}$ were found and the peaks at $613 \mathrm{~cm}^{-1}$ and $516 \mathrm{~cm}^{-1}$ were attributed to $\mathrm{Dy}_{2} \mathrm{O}_{3}$. In UV-Vis analyses, the photocatalytic properties of all composites were determined as a function of time at room temperature. 
The maximum transmittance variation occurred to be $75 \%$ at $800 \mathrm{~nm}$ wavelength for $\mathrm{Fe}_{2} \mathrm{O}_{3}-\mathrm{SiO}_{2}$, and the $2 \%$ at 425 and the $40 \%$ at $800 \mathrm{~nm}$ variations were observed for $\mathrm{Dy}_{2} \mathrm{O}_{3}-\mathrm{SiO}_{2}$. Here, the $\mathrm{Fe}_{2} \mathrm{O}_{3}$ $\mathrm{SiO}_{2}$, and $\mathrm{Dy}_{2} \mathrm{O}_{3}-\mathrm{SiO}_{2}$ rapidly absorbs the light around $300 \mathrm{~s}$. Moreover, the dark and light sensitivities of these composites were measured after waited in the dark and the light, separately. The absorbed light causes an increase at the transmittance in the 200-750 nm wavelength region. Consequently, in the dark, the new absorbed light could trigger the change in the short wavelength and the absorbed light from the initial measurement may not emit out of the sample. The magnetic behavior of these composites was defined by the hysteresis curves under $2 \mathrm{~T}$ magnetic field. The weak ferromagnetic behavior was observed in the $\mathrm{Fe}_{2} \mathrm{O}_{3}-\mathrm{SiO}_{2}$ and the composite can not reach a saturation. Therefore, we obtained the ferromagnetic part of this curve. For the ferromagnetic part, the saturation value for $\mathrm{Fe}_{2} \mathrm{O}_{3}-\mathrm{SiO}_{2}$ was found to be 0.15 $\mathrm{Am}^{2} \mathrm{~kg}^{-1}$. The obtained coercivity of the sample is $40 \mathrm{mT}$ under $2 \mathrm{~T}$ magnetic field. $\mathrm{Dy}_{2} \mathrm{O}_{3}-\mathrm{SiO}_{2}$ exhibited paramagnetic behavior as expected. The results show that these compositions can be produced with this facile method, and the $\mathrm{Fe}_{2} \mathrm{O}_{3}-\mathrm{SiO}_{2}$ and $\mathrm{Dy}_{2} \mathrm{O}_{3}-\mathrm{SiO}_{2}$ composites can absorb the UV-light at long wavelengths due to their photocatalytic properties. Hence, the results specify that the present composites could be applied for the developing photocatalytic materials, the optical fibers and electronic devices for light protection.

\section{ACKNOWLEDGMENTS}

We thank Asst. Prof. Dr. C. Gökhan Ünlü for assistances of scanning electron microscopy measurement. Also, we thank Mr. Kağan Şarlar for the magnetic measurements of the composites. This work was supported by the Commission of Scientific Research Projects of Uludag University [Project Number OUAP(F)-2018/4].

\section{REFERENCES}

1. S. Soltan, H. Jafari, S. Afshar, and O. Zabihi, Water Sci. Technol. 77, 1689 (2016). https://doi.org/10.2166/wst.2016.3 43.

2. S.C. Feifel and F. Lisdat, J. Nanobiotechnol. 9, 59 (2011). h ttps://doi.org/10.1186/1477-3155-9-59.

3. S.H. Huang and R.S. Juang, J. Nanopart. Res. 13, 4411 (2011). https://doi.org/10.1007/s11051-011-0551-4

4. C. Pacurariu, E.A. Taculescu, R. Ianos, O. Marinica, C.V. Mihali, and V. Socoliuc, Ceram. Int. 41, 1079 (2015). http s://doi.org/10.1016/j.ceramint.2014.09.031.

5. E. Esmaeili, M. Salavati-Niasari, F. Mohandes, F. Davar, and H. Seyghalkar, Chem. Eng. J. 170, 278 (2011). https://d oi.org/10.1016/j.cej.2011.03.010.

6. U. Schwertmann and R.M. Cornel, The Iron Oxides in the Laboratory, Preparation and Characterization (Weinheim: VCH Publishers, 1996).

7. M. Mishra and D.M. Chun, Appl. Catal. A: Gen. 498, 126 (2015). https://doi.org/10.1016/j.apcata.2015.03.023.
8. M. Salavati-Niasari, F. Davar, and M. Mazaheri, J. Alloys Compd. 470, 502 (2009). https://doi.org/10.1016/j.jallcom.20 08.03.048

9. M. Salavati-Niasari, P. Salemi, and F. Davar, J. Mol. Catal. A: Chem. 238, 215 (2005). https://doi.org/10.1016/j.molcata. 2005.05.026.

10. F. Beshkar and M. Salavati-Niasari, J. Nanostruct. 5, 17 (2015). https://doi.org/10.7508/jns.2015.01.003.

11. F. Motahari, M.R. Mozdianfard, F. Soofivand, and M. Salavati-Niasari, RSC Adv. 4, 27654 (2014). https://doi.org/10. 1039/C4RA02697G.

12. F. Soofivand, F. Mohandes, and M. Salavati-Niasari, Mater. Res. Bull. 48, 2084 (2013). https://doi.org/10.1016/j.materre sbull.2013.02.025.

13. M. Ranjbar, M. Salavati-Niasari, S.M. Hosseinpour-Mashkani, and K. Venkateswara-Rao, J. Inorg. Organomet. Polym Mater. 22, 1122 (2012). https://doi.org/10.1007/s1090 4-012-9704-x.

14. O. Amiri, M. Salavati-Niasari, S.M. Hosseinpour-Mashkani, A. Rafiei, and S. Bagheri, Mater. Sci. Semicond. Process. 27, 261 (2014). https://doi.org/10.1016/j.mssp.2014.06.020.

15. H. Zeynali, S. Behnam Mousavi, and S.M. HosseinpourMashkani, Mater. Lett. 144, 65 (2015). https://doi.org/10.10 16/j.matlet.2015.01.023.

16. N. Mir, M. Bahrami, E. Safari, and S.M. HosseinpourMashkani, J. Cluster Sci. 26, 1103 (2015). https://doi.org/10. 1007/s10876-014-0800-7.

17. A. Sobhani-Nasab, Z. Zahraei, M. Akbari, M. Maddahfar, and S.M. Hosseinpour-Mashkani, J. Mol. Struct. 1139, 430 (2017). https://doi.org/10.1016/j.molstruc.2017.03.069.

18. S. Zinatloo-Ajabshir, M.S. Morassaei, and M. Salavati-Niasari, J. Colloid Interface Sci. 497, 298 (2017). https://doi. org/10.1016/j.jcis.2017.03.031.

19. M. Mahdiani, F. Soofivand, F. Ansari, and M. Salavati-Niasari, J. Clean. Prod. 176, 1185 (2018). https://doi.org/10. 1016/j.jclepro.2017.11.177.

20. J. Balbuena, M. Cruz-Yusta, A. Pastor, and L. Snchez, J. Alloys Compd. 735, 1553 (2018). https://doi.org/10.1016/j.ja llcom.2017.11.259.

21. V.M. Bogatyrev, V.M. Gunko, M.V. Galaburda, M.V. Borysenko, V.A. Pokrovskiy, O.I. Oranska, E.V. Polshin, O.M. Korduban, R. Leboda, and J. Skubiszewska-Ziba, J. Colloid Interface Sci. 338, 376 (2009). https://doi.org/10.1016/j.jcis. 2009.06.044.

22. Q. Sun, W. Leng, Z. Li, and Y. Xu, J. Hazard. Mater. 229230 , 224232 (2012). https://doi.org/10.1016/j.jhazmat.2012.05.09 8.

23. X. Wang, C. Liu, X. Li, F. Li, and S. Zhou, J. Hazard. Mater. 153, 426433 (2008). https://doi.org/10.1016/j.jhazmat.2007.0 8.072 .

24. Y.B. Saddeek, K.H.S. Shaaban, R. Elsaman, A. El-Taher, and T.Z. Amer, Radiat. Phys. Chem. 150, 182 (2018). http s://doi.org/10.1016/j.radphyschem.2018.04.028.

25. M.S. Rao, B. Sanyal, K. Bhargavi, R. Vijay, I.V. Kityk, and N. Veeraiah, J. Mol. Struct. 1073, 174 (2014). https://doi.org/ 10.1016/j.molstruc.2014.04.075.

26. H. Huang, Y. Ou, S. Xu, G. Fang, M. Li, and X.Z. Zhao, Appl. Surf. Sci. 254, 2013 (2008). https://doi.org/10.1016/j.apsusc. 2007.08 .041$.

27. G.A.S. Josephine and A. Sivasamy, Environ. Sci. Technol. Lett. 1, 172 (2014). https://doi.org/10.1021/ez4002032.

28. G.A.S. Josephine and A. Sivasamy, Appl. Catal. B: Environ. 150-151, 288 (2014). https://doi.org/10.1016/j.apcatb.2013.1 1.004 .

29. A. Kumar, N. Yadav, M. Bhatt, N.K. Mishra, P. Chaudhary, and R. Singh, Res. J. Chem. Sci. 5, 98 (2015).

30. J.D. Mackenzie, J. Non-Cryst. Solids 100, 162 (1988)

31. A. Altomare, N. Corriero, C. Cuocci, A. Falcicchio, A. Moliterni, and R. Rizzi, J. Appl. Crystallogr. 48, 598 (2015). h ttps://doi.org/10.1107/S1600576715002319.

32. S. Vasanthavel, B. Derby, and S. Kannan, Inorg. Chem. 56,1273 (2017). https://doi.org/10.1021/acs.inorgchem.6b0 2361. 
33. S. Moshtaghi, S. Zinatloo-Ajabshir, and M. Salavati-Niasari, J. Mater. Sci.: Mater. Electron. 27, 425 (2016). https://doi. org/10.1007/s10854-015-3770-0.

34. A. Vazquez, T. Lopez, R. Gomez, Bokhimi, A. Morales, and O. Novaro, J. Solid State Chem. 128, 161 (1997). https://doi. org/10.1006/jssc.1996.7135.

35. A. Aronne, S. Esposito, and P. Pernice, Mater. Chem. Phys. 51, 163 (1997). https://doi.org/10.1016/S0254-0584(97)80287 $-8$.

36. W.L. Konijnendijk, Glastechn. Ber. 48, 216 (1975).

37. W.L. Konijnendijk and J.M. Stevels, J. Non-Cryst. Solids 21, 447 (1976). https://doi.org/10.1016/0022-3093(76)90033-8.

38. Y. Tsunawaki, N. Iwamoto, T. Hattori, and A. Mitsuishi, J. Non-Cryst. Solids 44, 369 (1981). https://doi.org/10.1016/00 22-3093(81)90039-9.

39. S. Maensiri, C. Masingboon, B. Boonchom, and S. Seraphin, Scripta Mater. 56, 797 (2007). https://doi.org/10.1016/j.scri ptamat.2006.09.033.

40. S. Zhang, Nanostructured Thin Films and Coatings: Functional Properties (Routledge: Taylor and Francis, 2010).

41. Y.B. Saddeek, K.H.S. Shaaban, R. Elsaman, A. El-Taher, and T.Z. Am, Proc. Indian Acad. Sci. 12A, 93 (1940).

42. V.C. Pierre and M.J. Allen, Contrast Agents for MRI. The Royal Society of Chemistry, London. (2018). https://doi.org/ 10.1039/9781788010146.
43. M. Arshad, A. Azam, A.S. Ahmed, S. Mollah, and A.H Naqvi, J. Alloys Compd 509, 8378 (2011). https://doi.org/10. 1016/j.jallcom.2011.05.047.

44. S. Muthu Kumaran and R. Gopalakrishnan, J. Sol-Gel Sci. Technol. 62, 193 (2012). https://doi.org/10.1007/s10971-0122708-8.

45. J. Pisarska, J. Phys.: Condens. Matter 21, 285101 (2009). h ttps://doi.org/10.1088/0953-8984/21/28/285101.

46. K. Kadono, N. Itakura, T. Akai, M. Yamashita, and T. Yazawa, J. Phys.: Condens. Matter 22, 045901 (2010). https://d oi.org/10.1088/0953-8984/22/4/045901.

47. R. Kant, D. Kumar, and V. Dutta, RSC Adv. 5, 52945 (2015). https://doi.org/10.1039/C5RA06261F.

48. T.P. Raming, A.J.A. Winnubst, C.M. van Kats, and A.P Philipse, J. Colloid Interface Sci. 249, 346 (2002). https://doi. org/10.1006/jcis.2001.8194.

49. D.X. Chen, V. Skumryev, and B. Bozzo, Rev. Sci. Instrum. 82, 045112 (2011). https://doi.org/10.1063/1.3581224.

50. D.J. Flood, Phys. Lett. A 49, 59 (1974). https://doi.org/10. 1016/0375-9601(74)90668-9.

Publisher's Note Springer Nature remains neutral with regard to jurisdictional claims in published maps and institutional affiliations. 